\title{
Relationship between mother's knowledge and behaviour with oral health status of early childhood
}

\author{
Munifah Abdat ${ }^{1 *}$, Ivan Ramayana ${ }^{2}$ \\ ${ }^{1}$ Department of Dental Public Health, Faculty of Dentistry Syiah Kuala University, Indonesia \\ ${ }^{2}$ Department of Internal Medicine, Faculty of Medicine Syiah Kuala University, Indonesia
}

\begin{abstract}
Introduction: Early childhood period has a high caries risk that needs special attention from parents, especially the mothers, as their role models. Mothers' knowledge and positive behaviour towards oral health care are essential in preventive dentistry since it is the crucial thing that can support the children's oral hygiene. Purpose of study was aimed to analyse the relationship between the mother's knowledge and behaviour regarding oral health with the early childhood oral health status. Methods: Type of study was a cross-sectional study with correlational research method. The material from this research were questionnaires and standard instruments for an oral examination. The study was conducted on 44 children of the early childhood period and their mothers, which was chosen as sample using a purposive sampling technique for respondents who met the inclusion criteria. The inclusion criteria were mothers who took up their children to the mother and children's health centre, children in the early childhood period with complete deciduous teeth eruption, and willing to participate in the research. A Kendall's-tau test was used for statistical analysis. Results: The results showed that the def-t index was 7.6 (very high) and there was a significant relationship between mother's knowledge ( $p$-value $=0.0001)$ and behaviour ( $p$-value $=0.004)$ towards oral health status of the children (def-t index). The results also showed strong correlation coefficient to knowledge $(\tau=-0.643)$ and sufficient correlation coefficient to behaviour $(\tau=$ -0.415). Ironically, mothers with sufficient knowledge regarding the children's oral health are not fully reflected in daily oral hygiene practice. The mean value of caries teeth in each child was seven teeth, mostly found in children with mothers with poor oral health knowledge and behaviour. Conclusion: There is a strong relationship between mother's knowledge and oral health status of early childhood, while the mother's behaviour and oral health status has a moderate relationship.
\end{abstract}

Keywords: Children's oral health, mother's knowledge and behaviour.

p-ISSN: 1979-0201; e-ISSN: 2549-6212; Available from: http://jurnal.unpad.ac.id/pjd/article/view/24734

DOI: 10.24198/pid.vol32no2.24734

Submission: Nov 23, 2019; Accepted: Aug 31, 2020; Published online: Nov 30, 2020

"Corresponding author: Munifah Abdat, Department of Dental Public Health, Faculty of Dentistry Syiah Kuala University, Indonesia. Department of Dental Public Health, Faculty of Dentistry Syiah Kuala University, Jalan Teuku Nyak Arief Darussalam, Banda Aceh, Aceh, Indonesia, 23111. Phone: +6281317577701; Email: munifahabdat dr@unsyiah.ac.id 


\section{INTRODUCTION}

Oral health is an integral component of good general health, which plays a significant role in life, especially children. Various conditions of the oral cavity; dental caries, malposition, and discolouration, which may impact children's oral health. ${ }^{1}$ The results of the Indonesia Basic Health Research (Riskesdas) in 2018 showed the prevalence caries in Indonesian children experiencing caries is $93 \% .^{2}$ More than $25 \%$ of young children experience problems with their teeth in Aceh Province and most of the urban areas including Banda Aceh. ${ }^{2}$ According to the results of the oral examination of children in the city of Banda Aceh by health workers in the Community Health Centre showed that $65 \%$ of them suffer from caries. ${ }^{3}$

Mothers have a role in teaching oral hygiene, eating habits, and another healthy practice to their children from an early age. ${ }^{4}$ Mother is an essential model of parental knowledge for the children's right and poor oral hygiene behaviour development. ${ }^{1,4}$ The poor knowledge will cause the children's poor oral health behaviour, and good knowledge will cause the children's good oral health behaviour and will develop good oral health habits. ${ }^{1,5}$ Parents' knowledge and positive attitudes towards good oral care are essential in the prevention cycle, as the primary components in maintaining oral hygiene.

Based on these fundamentals, researchers were interested in comparing the mother's knowledge and behaviour regarding oral health with the early childhood oral health status at the mother and child's health centre in Ulee Kareng, Banda Aceh. The present study was aimed to analyse the relationship between the mother's knowledge and behaviour regarding oral health with the early childhood oral health status.

\section{METHODS}

The type of study was an analytical study with a cross-sectional design. The study was conducted in January 2018. Forty-four childhood from Pango Raya and lemasen villages, Ulee Kareng subdistrict, Banda Aceh City, were examined, and a questionnaire was collected from their mothers. The subjects consisted of 44 children aged 2-5 years, and their mothers who met the inclusion criteria were chosen as samples using a purposive sampling technique. The inclusion criteria in this study were mothers who took up their children to Mother and Children Health Centre, children with complete deciduous teeth eruption, and willing to participate in this research. The research was approved by the Ethical Review Committee of the Faculty of Dentistry Syiah Kuala University, with the ethical clearance number of 099/KE/FKG/2019.

Data were collected based on the questionnaire, followed by oral examination. The questionnaire was adopted from the questionnaire of the research conducted by Sami et al. ${ }^{1}$ The questions regarding parents' knowledge and attitude towards oral health were the factors causing caries, staining, children's habit, malocclusion, the importance of tooth brushing, use of fluoride, and frequency of dental visit. The validity and reliability of the questionnaire was confirmed by the Cronbach coefficient $a$ ( $a=$ 0.91). After the subject agreed, the questionnaire was given and designed to be filled out by mothers in approximately 10 minutes. Results of the questionnaire about knowledge and behaviour are further categorised through scoring, which was categorised as follows: good if the score was 76 $100 \%$; sufficient or moderate if the score was 56 $75 \%$; poor if the score was $\leq 55 \%$.

The tools and materials used in this study were 44 sets of basic equipment (mirrors, explorer, cotton pliers, excavators) that have been sterilised with autoclaves, wipes, containers for sterilisation, disinfectant liquid, masks, and gloves. The researcher asked for approval from the respondents by signing an informed consent after explaining the research procedures. Then the researchers collected research subjects that fit the inclusion criteria. The researcher team consisted of four members, included the two examiners, questionnaire distributor, and examination results recorder-the questionnaire to be filled in 10 minutes.

After the questionnaire was completed, the children's teeth were examined, and the research form was filled out. The examination included the examination of the status of the children's deciduous teeth using a def-t index (decay (d), extracted (e), and filling (f) tooth). The def-t measurements of a group can be done by adding up all of the def values divided by the number of 
people examined. The calculation result of def- $t$ index was categorised as follows; very low $=0.0$ 1.1; low $=1.2-2.6$; medium $=2.7-4.4$; high $=4.5$ 6.5 ; and very high $=>6.6$. The data obtained was then entered into a Microsoft Excel database, and analysed statistically afterwards with Statistical Package for Social Science (SPSS) version 24.0 and presented in tabular form and description. Statistical analyses included descriptive statistics, and Kendall's-tau test were performed in advance. The significance level was set at the $p$-value of 0.05 .

\section{RESULTS}

Table 1 suggests that mothers with good oral health knowledge were 10 mothers $(22.7 \%)$, moderate was found in 22 mothers (50\%), and poor were 12 mothers (27.3\%). Meanwhile, mothers with good oral health behaviour was 9 mothers (20.5\%), moderate was 21 individuals $(47.7 \%)$, and poor was 14 mothers (31.8\%). The measurement results using the def-t index in the children were 7.6, which suggested a very high category.

Table 1. Frequency distribution of respondents based on mother's knowledge and behaviour on oral health

\begin{tabular}{llc}
\hline \multicolumn{1}{c}{ Variable } & $\mathrm{N}$ & (\%) \\
\hline Mother's knowledge & & \\
\hline Good & 10 & 22.7 \\
Moderate & 22 & 2250 \\
Poor & 12 & 27.3 \\
\hline Mother's behaviour & & \\
\hline Good & 9 & 20.5 \\
Moderate & 21 & 47.7 \\
Poor & 14 & 31.8 \\
Notes: $\mathrm{N}=$ Number of patients; \% & Percentage
\end{tabular}

Based on table 2, the def-t examination results showed that 29 children (65.9\%) had a high def-t index $(>4)^{5}$, while 15 children $(34.1 \%)$ had low def-t index $(\leq 4) .6$

Table 2. Def-t index measurement results based on number of child and percentage

\begin{tabular}{ccc}
\hline Caries index & Number & $\%$ \\
\hline Low $\leq 4$ & 15 & 34.1 \\
High $>4$ & 29 & 65.9 \\
\hline Notes: $\%=$ Percentage & &
\end{tabular}

Notes: $\%=$ Percentage

As much as 30 teeth of the pre-school children was found of having low $(\leq 4.4)$ dental caries $(\mathrm{d}-\mathrm{t})$ value, and 300 teeth was found of having high dental caries $(\mathrm{d}-\mathrm{t})$. Two teeth was extracted due to caries (e-t), and 6 teeth was filled (f-t) (Table 3).

Table 3. Def-t index measurement results based on the value of $d-t, e-t$, and $f-t$

\begin{tabular}{cccc}
\hline Caries index & $\Sigma$ d-t & $\Sigma$ e-t & $\Sigma$ f-t \\
\hline Low $(\leq 4)$ & 30 & 0 & 0 \\
High $(>4)$ & 300 & 2 & 6 \\
\hline Notes: $\Sigma=$ Total number & & &
\end{tabular}

Notes: $\Sigma=$ Total number

Table 4. Mean of the def- $t$ index of the children

\begin{tabular}{ccc}
\hline Criteria $(\mathrm{n}=44)$ & Mean & $\%$ \\
\hline def-t & 7.6 & 97.7 \\
d-t & 7.5 & 97.3 \\
e-t & 0 & 97.7 \\
f-t & 0 & 93.2 \\
\hline
\end{tabular}

Notes: \% $=$ Percentage

Table 4 shows that the mean value of the def-t was 7.6 (97.7\%), which included in the very high category, with the $\mathrm{d}$ - $\mathrm{t}$ average was 7.5 $(97.3 \%)$, the e-t average was $0(97.7 \%)$, and the $f-t$ average was 0 (93.2\%).

Table 5. Mother's knowledge on the children oral hygiene $(\mathrm{N}=44)$

\begin{tabular}{|c|c|c|c|c|}
\hline \multirow{2}{*}{ Mother's knowledge } & \multicolumn{2}{|c|}{ Yes } & \multicolumn{2}{|c|}{ No } \\
\hline & Number & $\%$ & Number & $\%$ \\
\hline Toothbrushing can prevent oral health problems & 44 & 100 & 0 & 0 \\
\hline Frequent consumption of sweet, sticky, and acidic foods can cause oral cavities & 41 & 93.1 & 3 & 6.81 \\
\hline Fluoride can prevent cavities & 22 & 50 & 22 & 50 \\
\hline Excess of fluoride can affect children's teeth & 14 & 31.8 & 30 & 68.1 \\
\hline It is important to know the eruption sequence & 13 & 29.5 & 31 & 70.4 \\
\hline It is important to know that problems in deciduous teeth will affect the permanent teeth & 12 & 27.2 & 32 & 72.7 \\
\hline $\begin{array}{l}\text { Children habits, such as thumb sucking, tongue thrusting, and nail-biting, can cause } \\
\text { tooth malposition }\end{array}$ & 23 & 52.2 & 21 & 47.7 \\
\hline Visiting the dentist regularly is important to maintain the oral health of your children & 22 & 50 & 22 & 50 \\
\hline
\end{tabular}


Data presented in table 5 shows that all mothers $(100 \%)$ knew that toothbrushing could prevent oral health problems, while 41 mothers (93.1\%) knew that frequent consumption of sweet, sticky, and acidic food could cause tooth cavities.

It was found that the number of mothers who did not know that fluoride could prevent cavities was 22 mothers (50\%) and also 30 mothers did not know that excess of fluoride will affect their children's teeth $(68.1 \%)$. A total of 31 mothers $(70.4 \%)$ did not know the tooth eruption sequence, and as many as 32 mothers $(72.7 \%)$ did not know the problem of deciduous teeth will affect the permanent teeth.

Of all subjects, 21 mothers (47.7\%) did not know that some habits of children, such as thumb sucking, tongue thrusting, and nail-biting can cause tooth malposition.

Table 6. Mother's behaviour on the children oral hygiene $(n=44)$

\begin{tabular}{|c|c|c|c|c|c|}
\hline \multirow{2}{*}{ No } & \multirow{2}{*}{ Mother's behaviour } & \multicolumn{2}{|c|}{ Yes } & \multicolumn{2}{|c|}{ No } \\
\hline & & Number & $\%$ & Number & $\%$ \\
\hline 1 & Supervise children while they brush their teeth & 40 & 90.9 & 4 & 9.09 \\
\hline 2 & Supervise the children's food intake & 31 & 70 & 13 & 29.5 \\
\hline 3 & Let the child sucking the bottle/pacifier when sleeping & 14 & 31.8 & 30 & 68.1 \\
\hline 4 & Considering that the tooth stain (discolouration) as a problem & 24 & 54.5 & 20 & 45.4 \\
\hline 5 & Considering that deciduous teeth are as important as permanent teeth & 25 & 56.8 & 19 & 43.1 \\
\hline 6 & $\begin{array}{l}\text { Breaking children's bad habits which cause malocclusion (teeth are not } \\
\text { properly aligned) }\end{array}$ & 26 & 59.09 & 18 & 40.9 \\
\hline 7 & Thinking that education about dental and oral health is important & 24 & 54.5 & 20 & 45.4 \\
\hline 8 & Take your child to have their teeth being examined regularly & 17 & 38.6 & 27 & 61.3 \\
\hline 9 & $\begin{array}{l}\text { Your personal experience with the dentist influences your decision to take } \\
\text { your child to the dentist }\end{array}$ & 14 & 31.8 & 30 & 68.1 \\
\hline 10 & $\begin{array}{l}\text { There are other people who influences the decision to choose the children's } \\
\text { oral care }\end{array}$ & 7 & 15.9 & 37 & 84.09 \\
\hline 11 & The children needs several types of oral health care & 16 & 36.3 & 28 & 63.6 \\
\hline
\end{tabular}

Data presented in Table 6 presents that as many as 40 mothers (90.9\%) monitored their children's toothbrushing habit, and 31 mothers (70.4\%) supervised the children's eating. As many as 27 mothers $(61.3 \%)$ did not take their children to the dentist, and 30 mothers $(68.1 \%)$ stated that both their personal experience and dentist did not

Table 7. Cross tabulation of mother's knowledge with def-t index

\begin{tabular}{cccccc} 
& \multicolumn{4}{c}{ Def-t index } \\
\cline { 3 - 6 } $\begin{array}{c}\text { Mother's } \\
\text { knowledge }\end{array}$ & Total & \multicolumn{2}{c}{ Low $(\leq 4.4)$} & \multicolumn{2}{c}{ High $(>4.4)$} \\
\cline { 3 - 6 } & & $\mathrm{N}$ & $\%$ & $\mathrm{~N}$ & $\%$ \\
\hline Good & 10 & 8 & 80 & 2 & 20 \\
Moderate & 22 & 6 & 27 & 16 & 73 \\
Poor & 12 & 1 & 9 & 11 & 91 \\
\hline Total & 44 & 15 & 34 & 29 & 66 \\
\hline
\end{tabular}

Description: $\mathrm{N}=$ Number of respondents; $\%$ = Percentage

Table 7 showed that the children with low def-t index were children of mothers with have good oral health knowledge (80\%), otherwise, while the children with high def-t index were children of mothers with poor oral health knowledge (91\%). influence their decision in taking their children to the dentist.

A total of 37 mothers (84.09\%) answered that no one influenced their decision to choose oral care for their children and as many as 28 mothers $(63.6 \%)$ stated that their children did not need oral health care.

Table 8. Cross tabulation of mother's behaviour with def- $t$ index

\begin{tabular}{cccccc}
\hline \multirow{2}{*}{$\begin{array}{c}\text { Mother's } \\
\text { behaviour }\end{array}$} & Total & \multicolumn{4}{c}{ Def-t index } \\
\cline { 3 - 6 } & & Low $(\mathbf{4} .4)$ & \multicolumn{1}{c}{ High $(>4.4)$} \\
\cline { 3 - 6 } & 9 & 7 & 78 & 2 & 22 \\
\hline Good & 21 & 6 & 28.5 & 15 & 71.5 \\
Moderate & 14 & 2 & 14 & 12 & 86 \\
Poor & 44 & 15 & 34 & 29 & 66 \\
Total & &
\end{tabular}

Description: $\mathrm{N}=$ Number of respondents; $\%$ = Percentage

Table 8 showed that the lowest def-t index value was found in children of mothers with good oral health behaviour (78\%). Meanwhile, the highest def-t index value was found in children of mothers with poor oral health behaviour (86\%). 
Table 9. Relationship between mother's knowledge and behaviour with def-t index

\begin{tabular}{lc}
\hline \multicolumn{1}{c}{ Variable } & P-value \\
\hline $\begin{array}{l}\text { Relationship between mothers' knowledge towards } \\
\text { the children's oral health status (def-t index) }\end{array}$ & 0.0001 \\
& \\
Relationship between mothers' behavior towards & 0.004 \\
the children's oral health status (def-t index) & \\
Kendall's-tau test: $(\mathbf{p}<0.05$ considered as significant)
\end{tabular}

Table 9 showed that there was a significant relationship between mothers' knowledge and behaviour regarding oral health care towards their children's oral health status (def-t index) $(p<0.05)$, with strong correlation coefficient to knowledge $(\tau=-0.643)$ and sufficient correlation coefficient to behaviour $(\tau=-0.415)$. A negative sign (-) means that the better the knowledge and behaviour of the mother, the lower the def- $t$ index of the children (good oral health status).

\section{DISCUSSION}

Oral health is an integral component of good general health and plays a significant role in children's life. Various diseases and conditions of the oral cavity such as dental caries, periodontal disease, malposition, and discolouration can cause problems in oral health status. Children of early age cannot take care of themselves and depending on their parents. ${ }^{1}$ Mother is the role model in the development of children's behaviour at the beginning of their lives. ${ }^{4}$ Behaviour that will positively and negatively affect the children's oral hygiene is based on parental knowledge. ${ }^{7}$

The results from this study show that the majority of the mothers had moderate knowledge category (50\%) and also the moderate behaviour regarding oral health $(47.7 \%)$, whereas the children's def-t index were mostly found in the high category. Following the research of Abduljalil et al. ${ }^{4}$ which stated that the mother's knowledge about the oral health of pre-school children is relatively good, however, unfortunately, this knowledge is not fully reflected in their practices. ${ }^{3,4}$

Oral health awareness has increased in the last century, but the prevalence of early childhood caries remains a significant clinical problem. Based on the results of this study, the def-t mean of the children was 7.6 (97.7\%), which included in the very high category with the decayed teeth average was 7.5 (97.3\%). This result was similar to the research of Susi et al. ${ }^{8}$, which suggested that dental caries status in pre-school children shows a very high category def-t index.

Averagely, a child suffering seven carious teeth in the present study, seven to eight missing teeth, and most of them were experiencing rampant caries. This type of caries occurs very quickly and affects several teeth and often causes pain that makes the children experiencing eating difficulty and become more cranky. Caries occurs because of microorganisms activity in plaque and saliva as a result of consuming processed foods containing sucrose between two meals and decreased salivary secretion. ${ }^{9}$

Children who have a high risk of caries should receive special attention, intensive care, and extra care must be taken to eliminate caries or at least reduce the high caries risk. Primary prevention measures are prevention carried out before illness, include brushing teeth twice a day in the morning after breakfast and at night before going to bed, using dental floss for interdental and regularly visiting the dentist every six months. ${ }^{10}$ However, several mothers have lack knowledge (27\%) and poor oral health behaviour (31\%) so that socialisation activities need to be continuously improved through mother and child health centres or other activities.

Behaviour is closely related to knowledge, and health information may improve subjects' knowledge so that it can raise awareness and cause behavioural change with their knowledge. ${ }^{7}$ Based on the results of the present research, it is known that $100 \%$ mothers were aware that toothbrushing can prevent oral health problems and $90.9 \%$ of mothers supervised their children when brushing their teeth. For as many as $93.1 \%$ agreed that consuming sweet food can cause tooth cavities, and $70.4 \%$ of mothers also supervised the type of their children's food.

This result was similar to the research conducted by Sami A et al. ${ }^{1}$, which stated that parents should know the importance of tooth brushing and sweet consumption for oral health. ${ }^{1}$ Caries can be reduced by removing plaque which is one component in caries formation. Removal of plaque can be done by brushing teeth, and also the usage of dental floss and mouthwash. ${ }^{2}$ Eating foods that contain carbohydrates too often may 
increase the potential of caries formation because dental enamel will not have time to remineralise. ${ }^{2}$

Fluoride, commonly called fluorine, in the right dose/concentration, is useful as caries prevention. Fluorine as a preventive method has been widely used in the world in various dosage forms such as mouth rinses, toothpaste, and others that must be used by professionals. ${ }^{11}$ To maximise the beneficial effects of fluoride in toothpaste, toothbrushing with fluoride toothpaste must be performed twice a day, and rinsing after brushing should be kept to a minimum or not performed entirely. ${ }^{12}$ Mothers' knowledge of fluoride usage in this study showed that $50 \%$ of mothers did not know that fluoride could prevent cavities and $68.1 \%$ of mothers did not know that excess fluoride could affect children's teeth.

In comparison, the study results of Abduljalil et al. ${ }^{4}$ suggested that as many as $64.7 \%$ of the parents know the role of fluoride in preventing tooth decay. Parents should be using no more than a large number (only with a peanut size) of fluoride toothpaste for children aged less than three years to reduce the risk of fluorosis.

The sequence of teeth growth in infants, deciduous teeth begins to grow around the age of 5 months. When babies are 18 months to 6 years old, twenty deciduous teeth are present. At the age of 2 years, children begin to brush their teeth and learn about dental hygiene practices from parents. If dental hygiene is ignored, then dental caries and dental irregularities will be a problem.

The present study revealed that as many as $70.4 \%$ of mothers did not know about the sequence of tooth growth, so they cannot take preventive steps and have an impact on the problem of dental caries in early childhood. The results of this study also showed that $72.7 \%$ of mothers did not know the problem of deciduous teeth affected permanent teeth. The growth of a child's permanent teeth was determined by the condition of the child's primary teeth. However, there are still many parents who think that deciduous teeth are only temporary and will be replaced by permanent teeth, so they often assume that damage to primary teeth is not a problem. ${ }^{13}$

As many as $47.7 \%$ of mothers did not know the habits of children such as thumb sucking, tongue thrusting, and nail-biting can cause tooth misalignment. At this level of development, the role of parents is needed, so that tooth misalignment and caries do not occur in children. Maintaining oral hygiene and improving child habits are needed to avoid problems in the future. ${ }^{13}$

Based on the current research, as many as $50 \%$ of mothers do not know the importance of visiting a dentist regularly to maintain children's oral health. It was revealed that $84.09 \%$ of mothers agreed that none influenced the decision to choose a child's oral care, including to the dentist. The present research also suggested that the behaviour of mothers who did not take their children to have their teeth routinely checked was as many as $61.3 \%$. Furthermore, it was revealed that $63.6 \%$ of mother's behaviour which was not affirmative stating that their children did not need oral care, this was in line with the high def- $t$ value, which was $65.9 \%$.

This result was not in accordance to the research conducted by Sami et al. ${ }^{1}$, which stated that parents should be encouraged to seek professional oral health counselling such as dentists regarding the selection of children's oral care after the primary teeth begin to erupt. ${ }^{1}$ Children should receive special attention, intensive care and extra care must be taken immediately to eliminate caries or at least reduce the risk of high caries by visiting the dentist every six months should be done as an effort to improve health and prevent oral diseases. Regular dental examinations can help in detecting the children's oral problems including tooth discolouration. ${ }^{2}$

Children with a low def-t index were children from the mothers with good oral health knowledge (80\%), whereas children with a high def- $t$ index were children from the mothers with poor oral health knowledge (91\%). The research conducted by Susi et al. ${ }^{8}$ also stated that the better the knowledge of mothers regarding oral health, the lower the def-t index value of their children. It is inversely proportional to the research of Enkhbold ${ }^{14}$, which suggested that parents' or caregivers' knowledge regarding oral health are good; however, dental caries is still found in their children, as shown in def-t index measurement. Children with high def-t index are still found (73\%) from mothers with only moderate knowledge. ${ }^{14}$

The current research also found that children with low def-t index was children from mothers with good oral health behaviour (78\%), 
and children with high def-t index was children from mothers with poor oral health behaviour $(86 \%)$. However, there were also found many children with high def-t index from mothers with moderate oral health behaviour (71.5\%). The study conducted by Enkhbold ${ }^{14}$ discovered that the parents' who bring their children to have regular dental examinations from the dentist were positively correlated to the children's low def-t index.

Knowledge and behaviour are inseparable things. Initiating good oral health habits critical to establish appropriate cultural and behavior. ${ }^{4}$ There was found a significant relationship between mother's knowledge and behaviour towards the children's oral health status $(p<0.05)$. Tang et al. ${ }^{15}$ stated that there was a significant relationship between parents'/caregivers' knowledge and behaviour towards early childhood caries. Parents may ignore the importance of deciduous teeth and consider primary teeth only as transitions; therefore, the decay of primary teeth will not affect permanent teeth, and primary teeth do not need to be treated. Errors in understanding oral health knowledge are found in parents or caregivers. ${ }^{15}$

However, Abduljalil et al. $^{4}$ stated that mothers' knowledge regarding the oral health of pre-school children was good, but unfortunately, this knowledge was not fully reflected in daily practices. Children's at an early age depends on their parents, especially their mother, as the role model in the development of their behaviour. The children's oral hygiene is essential and based on parental knowledge. ${ }^{1}$ Parents' knowledge and positive attitudes towards excellent oral care are critical in the prevention cycle. ${ }^{5}$ Supportive and unsupportive behaviour towards the children's oral hygiene is based on parents' knowledge. Tooth brushing, flossing, and professional prophylaxis recognised as the primary components in maintaining oral hygiene.

Tooth brushing skills had been taught and emphasised in children throughout their lifetime. Children under the age of 5-years cannot maintain their oral hygiene properly; thus, the parents must brush their child's teeth at least until the child aged six years old. ${ }^{16,17}$ Good oral health habits in children are the reflection of their parents' behaviour which positively affecting the children. ${ }^{5}$

\section{CONCLUSION}

There is a strong relationship between mother's knowledge and oral health status of early childhood, while the mother's behaviour and oral health status has a moderate relationship.

\section{REFERENCES}

1. Sami A, Fatima K, Moin H, Bashir R, Ahmed J. Relationship of parental knowledge and attitude with oral health status of children in Karachi East. Br J Med Med Res. 2016; 14(9): 1-9. DOI: $10.9734 / B J M M R / 2016 / 24767$

2. National Institute of Health Research and Development (NIHRD). Indonesia Basic Health Research (RISKESDAS) 2017-2018. Jakarta: Ministry of Health of the Republic of Indonesia; 2018.

3. Banda Aceh Public Health Office. 2014 Banda Aceh City Health Profile. Banda Aceh: Banda Aceh Public Health Office; 2014.

4. Abduljalil HS, Abuaffan AH. Knowledge and practice of mothers in relation to dental health preschool children. Adv Genet Eng. 2016; 5(2): 1-7. DOI: $10.4172 / 2169-0111.1000153$

5. Priya MM, Kumar P, Saraswathi S. Assessment of parental oral health knowledge, attitude, and behavior. J Pharm Res. 2018; 12(1): 47-50.

6. Supriatna A, Fadillah RPN, Nawawi AP. Description of dental caries on mixed dentition stage of elementary school students in Cibeber Community Health Center. Padjadjaran J Dent. 2017; 29(3): 153-7. DOI: 10.24198/pjd. vol29no3.14303

7. Al-Darwish MS. Oral health knowledge, behavior and practices among school children in Qatar. Dent Res J (isfahan). 2016; 13(4): 342-53. DOI: $10.4103 / 1735-3327.187885$

8. Susi, Murniwati, Nila Kasuma, Minarni. The relationship between maternal characteristics and early childhood caries. Padjadjaran J Dent. 2020; 32(1): 22-7. DOI: 10.24198/pjd. vol32no1.23640

9. New York State Department of Health. Oral Health Care during Pregnancy and Early Childhood Practice Guidelines. New York: New York State Department of Health; 2006. p.15.

10. Darby ML, Walsh MM. Dental Hygiene: Theory and Practice. $4^{\text {th }}$ ed. London: Elsevier Health 
Science; 2015: p. 400-2.

11. Pollick $\mathrm{H}$. The role of fluoride in the prevention of tooth decay. Pediatr Clin North Am. 2018; 65(5): 923-40. DOI: 10.1016/j.pcl.2018.05.014

12. American Academy of Pediatric Dentistry. The Reference Manual on Pediatric Dentistry Fluoride Therapy. Chicago: American Academy of Pediatric Dentistry; 2018. p. 263.

13. Eddy FNE, Mutiara H. Peranan ibu dalam pemeliharaan gigi anak dengan status karies anak usia sekolah dasar. Med J Lampung Univ. 2015; 4(8): 1-6.

14. Enkhbold K. The prevalance of sereve early childhood caries and associated oral health knowledge and behaviors of caregivers in ulaanbaatar, Mongolia [thesis]. Seoul: Seoul National University; 2017. p. 32.
15. Tang RS, Huang ST, Chen HS, Hsiao SY, Hu HY, Chuang $\mathrm{FH}$. The association between oral hygiene behavior and knowledge of caregivers of children with severe early childhood caries. J Dent Sci. 2014; 9(3): 277-82. DOI: 10.1016/j. jds.2013.02.025

16. Elison S, Norgate S, Dugdill L, Pine C. Maternally perceived barriers to and facilitators of establishing and maintaining tooth brushing routines with infants and preschoolers. Int J Environ Res Public Health. 2014; 11(7): 680826. DOI: $10.3390 /$ ijerph 110706808

17. Marshman Z, Ahern SM, MCEachan RRC, Rogers HJ, Gray-Burrows KA, Day PF. Parents' experiences of toothbrushing with children - A qualitative study. JDR Clin Trans Res. 2016; 1(2): 122-130. DOI: 10.1177/2380084416647727 